\title{
Dictadura militar argentina 1943-1946. Temor, rechazo y desconfianza en el Uruguay*/
}

\author{
Argentina's Military Dictatorship (1943-1946). \\ Fear, Rejection and Mistrust in Uruguay
}

\author{
Carolina Cerrano \\ ORCID iD: http://orcid.org/0000-0002-0541-9623 \\ Universidad de Montevideo-ANII \\ Fernando López D'Alesandro \\ ORCID iD: http://orcid.org/0000-0002-4357-1562 \\ Universidad de Montevideo
}

En este artículo se estudia cómo el Uruguay, y en concreto su gobierno, se posicionó ante la dictadura militar argentina de 1943 y 1946. El papel de los Estados Unidos fue fundamental en los lineamientos de la política exterior del pequeño país. A medida que el conflicto entre la Argentina y la «democracia del norte» se fue agravando, Uruguay se respaldó en su nuevo aliado poderoso para protegerse del «expansionismo» de su vecino y del ascenso del peronismo.

Palabras Clave: Argentina; Uruguay; Estados Unidos; Peronismo.

This paper examines the Uruguayan government position about Argentina's military dictatorship between 1943 and 1946. The role played by the United States was of utmost importance providing guidelines for the foreign policy of the small country. As the conflict between Argentina and the United States democracy got aggravated, Uruguay got more support from its new powerful ally, as well as protection from the expansionism of its neighbor, and from the Peronism's rise to power.

KeYwords: Argentine; Uruguay; United States; Peronism.

Copyright: (C) 2017 CSIC. Este es un artículo de acceso abierto distribuido bajo los términos de una licencia de uso y distribución Creative Commons Attribution (CC-by) España 3.0.

* Este artículo se inscribe en el marco del proyecto de investigación: «El peronismo desde las dos orillas, 1943-1955», del Departamento de Historia de la Facultad de Humanidades y Educación de la Universidad de Montevideo. Los autores son sus responsables científicos. Una versión anterior de este artículo fue publicada en prensa uruguaya: Cerrano y López D’Alesandro, 2014. 
El golpe de Estado argentino de junio de 1943 y el posterior proceso peronista fueron interpretados de manera diversa en el Uruguay, pero el rechazo fue la norma, entre las élites liberales y de izquierda y entre la sociedad, a excepción del herrerismo. El surgimiento de una dictadura militar fundada en el nacionalismo católico despertó grandes reservas primero y graves temores después en un país de tradición democrática y laica. ${ }^{1}$ Las sospechas de nazi-fascismo de la «revolución de 1943» chocaron con el masivo apoyo al bando republicano en la guerra civil española y a los aliados en la Segunda Guerra Mundial. Y especialmente la intención de los militares de concebir una Argentina potencia, que actuara en el primer plano del concierto regional, suscitó resistencias en el país. Así pues, nuestro objetivo es estudiar la irrupción del proceso peronista y su recepción política en el Uruguay en los prolegómenos de la Guerra Fría. ${ }^{2}$

Desde la primera postguerra mundial, Uruguay consideraba el equilibrio de poderes regional como la herramienta principal de sus decisiones internacionales. En la Segunda Guerra, la neutralidad duró muy poco, y así fue como el gobierno del general arquitecto Alfredo Baldomir se alineó con los aliados y luego con las políticas panamericanistas de los Estados Unidos. ${ }^{3}$ Su sucesor, el presidente Juan José de Amézaga y sus cancilleres —José Serrato y Eduardo Rodríguez Larreta - siguieron la misma línea, aunque el segundo, durante su breve mandato proclamó una «doctrina», que habilitaba la intervención extranjera en caso de que hubiera gobiernos de corte totalitario. Como veremos, la Doctrina Larreta, además de ser una «sugerencia» norteamericana, estaba pensada en clave argentina.

En definitiva, si bien la política exterior norteamericana influyó directamente en las decisiones uruguayas respecto de su vecino platense entre 1943 y 1945, el Palacio Santos buscó custodiar cierta autonomía en las formas de relacionarse con Argentina. Pero conforme el conflicto del país

1 Para abordar el tema de las relaciones entre la Iglesia y el Ejército argentino durante el periodo 1943-1946: Zanatta, 1999. De la bibliografía sobre el nacionalismo en los orígenes del peronismo destacamos: Piñeiro, 1997 y Buchrucker, 1987. Halperín Donghi (2003) sitúa el debate intelectual argentino en el contexto de la Segunda Guerra. Asimismo la dictadura militar y posteriormente el presidente Juan Domingo Perón estrecharon amistad con la España de Franco: González de Oleaga, 2002; Figallo, 1992. Rein, 1995.

2 Sobre las relaciones argentino-uruguayas hay escasos e irregulares trabajos: Rodríguez Ayçaguer, 2004 (documento de trabajo que aborda el tema solo para el año 1943); Oddone, 2003 (libro con una introducción a una recopilación de documentos desclasificados del Departamento de Estado); Rilla, Brando y Quirici, 2013 (libro de divulgación sin trabajo de fuentes primarias); Mercado, 2015 (incluye un breve capítulo dedicado a las relaciones bilaterales).

3 Sobre la política exterior uruguaya en esta época: Oddone, 1990. 
vecino con los Estados Unidos se fue agravando, ${ }^{4}$ Uruguay mantuvo un equilibrio cada vez más difícil y «escorado» hacia su gran aliado, la «democracia del norte», que terminaron respaldando y utilizando la política internacional uruguaya contra la dictadura a la que calificaban de pro-nazi $\mathrm{y}$, luego, contra el peronismo.

\section{Los Estados Unidos, el Uruguay y la Argentina en la «revolución de 1943»}

El 4 de junio de 1943 las fuerzas armadas argentinas se sublevaron contra el presidente constitucional, Ramón Castillo. En un principio el proceso revolucionario no estuvo claro para la diplomacia uruguaya. No se había previsto la posibilidad de un golpe de Estado, y cuando finalmente se produjo fue parte del asombro y de la confusión general ante este nuevo gobierno que no definía su perfil. ${ }^{5}$ Las élites políticas uruguayas se dividieron inmediatamente ante la sublevación militar. El herrerismo mostró, en principio, simpatía por el «motín», o por qué no el inicio de una «auténtica revolución» se preguntaba, mientras hacía un llamado a la prudencia para esperar cómo se desarrollarían los acontecimientos. ${ }^{6}$ En las semanas siguientes el diario El Debate comenzó a hacer un uso constante de las medidas «moralizadoras» que se tomaban en la otra orilla platense como forma de castigar al gobierno de Amézaga. ${ }^{7}$ Para los socialistas, el golpe era la reacción ante el gobierno de Castillo y del fraude, también señalaban su decepción ante la dictadura que no solo eliminó las libertades, sino que había integrado al gobierno a notorios personeros de la época de Uriburu y

4 En cuanto a las relaciones argentino-norteamericanas durante el primer peronismo véase: Tulchin, 1990; Rapoport y Spiguel, 1994 y 2009.

5 Informe de Eugenio Martínez Thedy a José Serrato, Buenos Aires, 5 de junio de 1943, Archivo Histórico Diplomático, Ministerio de Relaciones Exteriores de Uruguay (AHDMREU), Fondo Ministerio de Relaciones Exteriores (MRE), serie Argentina, caja 3. El embajador uruguayo subrayaba que los golpistas se habían comprometido a regresar pronto al orden constitucional y que los partidos y los sindicatos estaban «en calma». El 10 de junio el Uruguay manifestó su reconocimiento al nuevo gobierno argentino. Telegrama de Martínez Thedy a MREU, Buenos Aires, 10 de junio de 1943, AHDMREU, Fondo MRE, serie Argentina, caja 3. Para más información en relación a las causas y primeras medidas del golpe de Estado, véase: Potash, 263-301; Rouquie, 1994, 9-21 y Halperín Donghi, 2004, 290 y ss.

6 «Ante los Sucesos Ocurridos», El Debate, 6 de junio de 1943; «De "los niños cantores" al 4 de junio», El Debate, 7 de junio de 1943. El Debate era el órgano periodístico del herrerismo.

7 «Moralización de la justicia», El Debate, 15 de junio de 1943; «La comunidad», El Debate, 23 de junio de 1943; «Mientras aquí se declama», El Debate, 10 de agosto de 1943; «La Argentina y su porvenir», El Debate, 25 de agosto de 1943. 
a filo-fascistas confesos. ${ }^{8}$ En el caso del comunismo, la ruptura institucional tenía «un acentuado corte nazificante» ${ }^{9}$ y apuntaban una temprana alianza con el herrerismo. ${ }^{10}$

El batllismo, al igual que el nacionalismo independiente, condenó el golpe y no tardó en calificarlo de filo-nazi significando un peligro para el Uruguay. Aunque, otra cosa era la política exterior del país. Sucedía, en realidad, que la diplomacia uruguaya estaba condicionada por sus compromisos producto del alineamiento pro-aliado ante la Segunda Guerra Mundial. ${ }^{11}$ Para el Palacio Santos resultaría un ajedrez muy complejo ubicarse ante la nueva situación argentina. Y en ese delicado equilibrio Uruguay debió sortear presiones y temores optando por la alianza con los Estados Unidos.

Uruguay era un punto estratégico para los Estados Unidos. Ubicado entre los dos colosos sudamericanos, permitía la rápida llegada tanto a Argentina como a Brasil, pero en el caso del primero significaba una base para detener la expansión del nazismo, considerando que la revolución de 1943 había dado el poder a simpatizantes del Eje. Washington invirtió en logística y en defensa en Uruguay, además de tenerlo como un aliado especialmente considerado.

Sin embargo, los norteamericanos no siempre obtuvieron lo que querían. Por ejemplo, en febrero de 1942, en un memorándum, el Departamento de Estado había solicitado permiso para operar aviones de patrulla y barcos de guerra en el Río de la Plata utilizando los puertos uruguayos. A su vez, pretendían hacer extensiva esa autorización a «los barcos de guerra ingleses comprendidos en las fuerzas de patrulla». ${ }^{12}$ No consta que ambas potencias hayan operado en el Río de la Plata ni en el espacio aéreo uruguayo en aquellos años. Esto no quiere decir que la cancillería «durmiera» el expediente o

8 «os Sucesos Argentinos», El Sol, primera semana de junio de 1943. El Sol era el diario del Partido Socialista del Uruguay.

9 «Sobre los sucesos argentinos. Palabra del Comité Ejecutivo del Partido Comunista del Uruguay», Diario Popular, 9 de junio de 1943. Diario Popular era el periódico del Partido Comunista local.

10 «En relación con los nazis argentinos: Herrera recrudece su prédica subversiva», Diario Popular, 9 de junio de 1943.

11 En enero de 1942, Uruguay rompió relaciones diplomáticas con el Eje; no obstante desde el principio de la contiende manifestó sus simpatías por las democracias. Recién el 21 de febrero de 1945 declaró la guerra a Alemania y Japón. Cfr. Rodríguez Ayçaguer, 2004, 13-21. Sobre el contexto político partidario en el marco de la segunda guerra: Frega, Maronna y Trochón, 1987.

12 Memorándum reservado y muy confidencial, Embajada de los Estados Unidos, Montevideo, 10 de febrero de 1942 (fecha de redacción) y 27 de julio de 1943 (como entrado), AHDMREU, Fondo MRE, serie Uruguay, caja 21. El asesor letrado de la cancillería, Gilberto Pratt de María, «entiende que debe indicarse al M.D.N [Ministerio de Defensa Nacional] que debe accederse a lo solicitado» con el acuerdo de Serrato. Memorándum secreto, Montevideo, 11 de noviembre de 1943, AHDMREU, Fondo MRE, serie Uruguay, caja 21. 
se desentendiera del tema; en realidad, la solicitud de 1942 fue un nuevo sondeo para intentar instalar bases norteamericanas en el territorio uruguayo. ${ }^{13}$

A principios de noviembre de 1943, el ministro de Guerra, general Alfredo Campos, informaba a Serrato que habían concluido las reuniones entre los ejércitos y las marinas uruguaya y norteamericana donde se completaron los protocolos a seguir en caso de que Uruguay fuera atacado. Se había acordado abastecimientos de armas, controles de las comunicaciones y estrategias de defensa inmediatas para proteger la infraestructura básica militar. Los norteamericanos exigían los informes detallados de sus puertos, aeropuertos, ferrocarriles, carreteras, hospitales, depósitos de abastecimientos de combustibles, información clave y estratégica que se ofrecería pues los oficiales uruguayos, general Sicco y contraalmirante Schröeder, estuvieron «completamente de acuerdo» en brindarla. Inclusive el memorándum advierte que se debería hacer una campaña para justificar el accionar de las fuerzas armadas de los Estados Unidos «para oponerse a acusaciones de la radio y la prensa de "Imperialismo Yankee", etc.». Finalmente, el 18 de noviembre, el gobierno de Amézaga denegó la autorización a estas medidas. ${ }^{14}$ El rechazo seguramente tenía sus razones y hay que buscarlas en la región y en cierto nacionalismo. El acuerdo del paso de tropas por su territorio antes de que se desatara un conflicto dejaba abierta la posibilidad de que Washington, si la relación con Argentina se calentaba, utilizara al Uruguay como base haciendo cumplir los acuerdos firmados. En otro orden, entregar a una potencia, por más aliada o amiga que fuera, información estratégica es algo que ningún gobierno sensato permite ni habilita. Además, si el acuerdo trascendía, la situación del país sería terriblemente incómoda y quedaría ante el mundo, no como un aliado, sino como la base de operaciones norteamericana en la región. Y esto último, probablemente, hacía temer al gobierno la reacción argentina.

Mientras tanto Argentina, necesitada de armas y bloqueada en el abastecimiento por Estados Unidos, ${ }^{15}$ decidió, increíblemente, en 1943 esperarlo de Alemania. Esto fue descubierto y el 26 de enero de 1944 se rompieron

13 En 1940, los Estados Unidos habían intentado instalar bases aeronavales en el Uruguay, pero el proyecto fue frustrado por el partido nacional y su contraria votación en el senado. Sobre este tema se sugiere el libro del diplomático y periodista Mercader (1999), quien traza un panegírico de Luis Alberto de Herrera.

14 Memorándum secreto, Montevideo, 11 de noviembre de 1943 y nota del 18 de noviembre, AHDMREU, Fondo MRE, serie Uruguay, caja 21.

15 El tema de las frustradas compras de armamentos en los Estados Unidos forma parte de la controversial relación de la Argentina: Rapoport y Spiguel, 2009, 25, 33-34, 40 y 44-45; Potash, 1985, 316-319 y Rouquie, 1994, 33-36. 
relaciones con el Eje. No se creyó en la sinceridad de la ruptura, pero esta precipitó la crisis en el gobierno militar. El 24 de febrero Ramírez se «alejó» del cargo aduciendo «cansancio» y delegando el mando en el vicepresidente general Edelmiro J. Farrell. ${ }^{16}$ Para Uruguay, su caída fue una complicación más a su delicado equilibro diplomático regional y global. ${ }^{17}$ Los norteamericanos estaban convencidos de que había sido un golpe - no era exactamente una deducción sagaz, aunque importante conclusión a pesar de lo simple-y que respondía a presiones nacionalistas. ${ }^{18} \mathrm{El}$ desplazamiento de Ramírez afectaba «la seguridad del hemisferio», dijo Norman Armour, embajador norteamericano, a Eugenio Martínez Thedy, embajador uruguayo, ambos acreditados en Buenos Aires. Seguramente producto de estos intercambios fue que el ministro Serrato elevó al gobierno un informe subrayando el enfoque norteamericano: Farrell era un pro nazi y por tanto «sugería» a los gobiernos americanos que «estudiaran» el tema de forma «cuidadosa», pues Estados Unidos no reconocería al gobierno argentino. ${ }^{19}$ Por supuesto que el lenguaje diplomático de «la gran democracia del norte» implicaba, casi, órdenes y una presión imperial, en el sentido más sutil del término, para el alineamiento con su posición. Las prevenciones de Washington eran tales que consideraban el golpe de Farrell y el ascenso del coronel Juan Domingo Perón al ministerio de Guerra como «una maniobra destinada a impedir la cooperación de la Argentina con las naciones hermanas en la actual emergencia militar y a reanudar la cooperación argentina con las potencias del Eje». ${ }^{20}$

Para el gobierno uruguayo aquellos días fueron críticos. El nuevo régimen argentino casi no tenía adeptos en Uruguay — con la excepción

16 Una revisión historiográfica sobre la neutralidad argentina en Rapoport, 1995. En relación a los sucesos que llevaron a la ruptura de relaciones diplomáticas con el Eje y el ascenso de Farrell, ver: Potash, 1985, 319-20 y 329-340; Rouquie, 1994, 42-46. Ramírez renunció de forma definitiva a la presidencia el 9 de marzo de 1944 .

17 Carta de Martínez Thedy a Serrato, Buenos Aires, 25 de febrero de 1944, AHDMREU, Fondo MRE, serie Argentina, caja 4.

18 Memorándum, Montevideo, 28 de febrero de 1944, AHDMREU, Fondo MRE, serie Argentina, caja 4.

19 Idem. Telegrama (R.1102) de Martínez Thedy a Serrato, Buenos Aires, 29 de febrero de 1944, AHDMREU, Fondo MRE, serie Argentina, caja 4. En este último documento se informaba que «el Embajador de Estados Unidos ha recibido instrucciones de su Gobierno [...] que se abstenga de producir todo acto que signifique reconocimiento hasta nueva orden».

20 Memorándum, Montevideo, 28 de febrero de 1944, AHDMREU, Fondo MRE, serie Argentina, caja 4. «La actitud del Departamento de Estado fue no reconocer al gobierno argentino basándose en la "Doctrina Guani" - elaborada por un ministro de Relaciones uruguayo- que requería previa consulta entre los miembros de la Unión Panamericana antes de que cada uno de ellos estableciera relaciones con un gobierno no elegido constitucionalmente», Rapoport y Spiguel, 2009, 42. Una excelente y ya clásica biografía de Perón es la de Page, 2005. 
del herrerismo-, pero la razón de Estado implicaba mantener los canales abiertos con un vecino al que cada día veían con mayor aprensión o temor. Los informes de Martínez Thedy querían tener un atisbo de esperanza: Farrell continuaría la política de ruptura con el Eje que le había costado la presidencia a Ramírez, ${ }^{21}$ lo que significaba muy poco, pues luego del paso dado por su antecesor sería casi absurdo que se volviera a abrir una embajada en Berlín. Probablemente la endeble situación de un gobierno que recién se establecía generó en los observadores y analistas diplomáticos la percepción de que la caída de Ramírez había abierto un período de inestabilidad, que no podía sostenerse mucho tiempo al estar a contramano de la realidad del continente. ${ }^{22}$ El Departamento de Estado se encargó de terminar con las ilusiones de cambio: Argentina debía dar los «pasos necesarios para volver total y completamente al redil de la solidaridad hemisférica». ${ }^{23}$ Una presión de estas características era inadmisible para cualquier gobierno, y sobre todo para uno de corte nacionalista. El gobierno Farrell-Perón se encerró en su actitud soberanista, la que chocaba totalmente con las exigencias norteamericanas no por el contenido, sino por el estilo de la imposición y el tono de obligatoriedad que atizó el sentimiento antiimperialista forjado por la «revolución del 43».

El gobierno uruguayo apoyó a Estados Unidos, aunque trataba de mantener un equilibrio sensato con el vecino y cierto decoro público en la política internacional. El Departamento de Estado sabía los «riesgos» que corría el Uruguay en su vínculo con Argentina. ${ }^{24}$ Quizá esta prevención haya sido abonada por el informe secreto donde por primera vez encontramos —en la documentación diplomática uruguaya - nombrado al GOU (Grupo de Oficiales Unidos) y sus planes de tono expansionista. ${ }^{25}$ Un espantado «agente»

21 Nota confidencial y telegrama de Martínez Thedy a Serrato, Buenos Aires, 2 y 3 de marzo de 1944, AHDMREU, Fondo MRE, serie Argentina, caja 3.

22 Telegrama (B. 1055) de Martínez Thedy a Serrato, Buenos Aires, 29 de febrero de 1944, AHDMREU, Fondo MRE, serie Argentina, caja 3.

23 Washington, texto de la declaración de Mr. Stettinius, según un despacho de la United Press, 4 de marzo de 1944, AHDMREU, Fondo MRE, serie Argentina, caja 4. La Argentina «para cooperar en la defensa hemisférica» debía internar a los diplomáticos, militares y otros agregados de las potencias del Eje; «evitar los contrabandos de exportación de materias críticas»; reprimir las comunicaciones entre el país y las capitales del Eje y finalmente «cortar todas las operaciones financieras y comerciales con las firmas nacionales del Eje».

24 Juan Carlos Blanco (embajador uruguayo en Estados Unidos) a Serrato, personal y confidencial, Washington, 12 de marzo de 1944, AHDMREU, Fondo MRE, serie Argentina, caja 4.

25 Sobre el GOU, se recomienda el clásico libro de Potash, 1982. El GOU fue una logia militar de carácter nacionalista y proclive a tendencias corporativistas a la que perteneció Perón. Según Zanatta $(2013,13)$, el GOU fue el «alma del nuevo régimen». 
informó el 17 de marzo de la existencia de «un ambiente de agresividad progresiva, dentro de cierto núcleo de oficiales del ejército [argentino], en contra el Uruguay $[s i c] »$. El miedo era que en el «corto plazo» se buscara alguna excusa que llevara a «una medida extrema». ¿Había una hipótesis de invasión, o por lo menos de tensar la relación con Uruguay al límite? No lo sabemos aun, pero la medida prevista debería ser grave ya que el informante destacaba que, de ser activado el plan, se podría «convulsionar con la medida a este continente». ${ }^{26}$ Los temores existían, el gobierno de Amézaga no tardó en tomar prevenciones consultando a su homólogo británico. La respuesta mostraba admiración por el valor y la actitud uruguaya. ${ }^{27} \mathrm{Su}$ viejo aliado, que en 1944 se encontraba en franca decadencia, no lo dejaría solo en el conflicto con Argentina. Si bien Uruguay valoraba, y mucho, el apoyo anglo-norteamericano, también abrigaba esperanzas de restablecer «relaciones normales» con Buenos Aires, para lograr la estabilidad. ${ }^{28}$ No solo por una cuestión de buena vecindad que permitiera un relacionamiento armonioso, sino con el objetivo de la reconstrucción de las relaciones internacionales globales del mundo que vendría. ${ }^{29}$

El gobierno uruguayo intentaba convencer a los Estados Unidos de que el «bloqueo diplomático» era equivocado, aunque sin abandonar el lazo de solidaridad en su pulseada con Buenos Aires. El 17 de mayo, Martínez Thedy trató de convencer al embajador Armour de que la táctica empleada no era «la más acertada para solucionar el problema. Que era desconocer la psicología latino americana [sic] el emplear procedimientos coercitivos que afectan la dignidad ciudadana». ${ }^{30}$ Este intento de hacer entender a Estados Unidos las buenas razones para el cambio de táctica formó parte de

26 Documento sin título, al final del manuscrito aparece: del agente en Buenos Aires, 17 de marzo de 1944, AHDMREU, Fondo MRE, serie Argentina, caja 4. Vale la pena destacar que Perón disolvió el GOU a fines de febrero de 1944 en el contexto de la delegación del mando de Ramírez por Farrell, por lo cual es dudosa la fecha del documento.

27 Memorándum confidencial, Legación británica, Montevideo, 30 de marzo de 1944, AHDMREU, Fondo MRE, serie Argentina, caja 4, carpeta 7. El documento señala la «grave ansiedad» del gobierno de Amézaga y refleja serias dudas respecto a que el «bloqueo diplomático fuera la única solución al problema argentino».

28 Documento confidencial, Montevideo, 11 de abril de 1944, AHDMREU, Fondo MRE, serie Argentina, caja 4, carpeta 7.

29 Serrato sostenía: «Yo por mi parte me había hecho ilusiones de un mundo más justo, más democrático y menos imperialista y dominador que el que parece se está elaborando». Carta de Serrato a Blanco, Montevideo, 6 de octubre de 1944, AHDMREU, Fondo MRE, serie Argentina, caja 4.

30 Documento sin título, 17 de mayo de 1945, AHDMREU, Fondo MRE, serie Argentina, caja 4. Y se atrevió a ir más lejos: «Uruguay mantendría por el momento la situación que tiene, siempre que Estados Unidos, Inglaterra y Brasil no modifiquen las suyas, pero entiendo que el impasse no puede continuar sin que el Uruguay corra serios y graves riesgos». 
las «ilusiones» de una probable distensión. Esto sonaba bastante realista, teniendo en cuenta que la segura derrota de Alemania obligaría a Argentina a asumir una posición pro aliada, si quería romper su aislamiento y entrar en el concierto de los países que estaban creando las Naciones Unidas.

Dos días después de la gestión de Martínez Thedy, Washington definió su política pero no en los términos esperados. En un extenso memorándum, «muy confidencial», enviado a todos los países de América Latina se fijaba la posición sobre Argentina y las medidas a tomar. Según Cordell Hull, por ese entonces secretario del Departamento de Estado, Argentina utilizaría «arteramente» las celebraciones del 25 de mayo como una forma de lograr cierto reconocimiento de hecho, gracias a la concurrencia de los embajadores a los festejos. El «régimen no ha tomado medidas efectivas para complementar la ruptura de relaciones con el Eje», o sea Estados Unidos creía, y todos los gobiernos americanos debían considerarlo así, que los vínculos de Buenos Aires con Alemania seguían y se traducían en la protección que le ofrecían a jerarcas diplomáticos germanos. ${ }^{31}$

Para Hull, «la ingerencia contínua [sic] del régimen argentino en los asuntos internos de otros países americanos constituye una grave amenaza a la unidad continental». ${ }^{32}$ En conclusión, los Estados Unidos «no pueden concebir que se reconozca al régimen argentino a menos que este por medio de sus actos demuestre un cambio completo y fundamental de política y una consagración definitiva y sincera a la causa de las Naciones Unidas». ${ }^{33}$ Estados Unidos se empleó a fondo con el fin de doblegar al díscolo del hemisferio, incluyendo extremar las sanciones económicas; y no se daba cuenta de que en realidad avivaba el sentimiento nacionalista, tal como había sugerido evitar el prudente gobierno uruguayo. Sin embargo, el Ministerio de Relaciones Exteriores uruguayo, dejando a un lado sus propios consejos, decidió no participar en los actos del 25 de mayo (banquete y evento en el Teatro Colón), con excepción del Te Deum por ser una ceremonia religiosa,

31 Asimismo llamaban la atención de que el gobierno militar no había intervenido las principales firmas comerciales nazis, ni había cesado los negocios de las reparticiones del gobierno con estas. Tampoco había cerrado medios de propaganda filo fascista, ni había ilegalizado las organizaciones pro Eje. Para la diplomacia norteamericana era inadmisible que no se restringieran los cruces de frontera a «personas sindicadas de actividades a favor del Eje que ponen en peligro la seguridad del hemisferio». En contrapartida, el gobierno argentino había confiscado empresas inglesas y norteamericanas y había censurado agencias informativas de los aliados, mientras «ha observado una actitud benévola hacia las publicaciones y las actividades de propaganda del Eje». Muy confidencial, Departamento de Estado, 19 de mayo de 1944, AHDMREU, Fondo MRE, serie Argentina, caja 4.

32 Idem.

33 Idem. 
pero para ello contó con el aval norteamericano. ${ }^{34}$ Que un gobierno que se vanagloriaba de su laicidad tomara esta posición explica por sí solo los vaivenes a los que se vio expuesto para mantener la alineación con los aliados. Para los gobernantes argentinos, el boicot a los festejos patrios había sido demasiado evidente y molesto, y peor aun, había contado con casi la unanimidad de las naciones americanas, a excepción de México. ${ }^{35}$ Martínez Thedy, al igual que Armour, esperaba que el conflicto se pudiera resolver a la brevedad. ${ }^{36}$

El optimismo duró poco, el 24 de junio de 1944, Hull informó que el gobierno norteamericano decidió «romper el impasse» y «como primer paso ha llamado al embajador Armour para consulta», y esperaba que todos los países hicieran lo mismo «durante la próxima quincena». ${ }^{37}$ La presión se hizo sentir, especialmente en Uruguay, un punto geoestratégico fundamental. Pero para el gobierno oriental el retiro de su embajador le generaba un dilema político muy difícil. Al fin y al cabo, el deber de Amézaga y Serrato era velar por los intereses de su país y el más importante de ellos era el mantenimiento de la integridad territorial y de la paz. Estados Unidos solicitaba una medida de fuerza, en un momento en que circulaban versiones de la existencia de fuertes tendencias internas en el gobierno argentino que propiciaban el objetivo de pasar a ser el eje geopolítico de América del

34 Documentos sin títulos, Montevideo, 19, 20, 22 y 24 de mayo de 1944, AHDMREU, Fondo MRE, serie Argentina, caja 4. El argumento de Hull era que el gobierno argentino ponía en peligro la independencia de las repúblicas latinoamericanas, y le preocupaba la creciente tendencia a considerar que la guerra ya estaba ganada y que no hubiera necesidad de cooperación entre las naciones del continente.

35 Gracias al trato preferencial, Martínez Thedy recibió del embajador Armour un largo relato de la entrevista que había tenido con el general Peluffo, coronel Perón y contralmirante Tessaire. Los militares argentinos no querían aparecer frente a la opinión pública cediendo ante las presiones norteamericanas, pues quedarían en contradicción con el discurso nacionalista predicado desde 1943. Armour insistió en que se necesitaba «algún hecho concreto» que diera cuenta de un cambio en la política internacional. , Telegrama, Buenos Aires, 23 de mayo de 1944 y correspondencia del 8 de junio de 1944, AHDMREU, Fondo Legaciones y Embajadas, sección Argentina, caja 1, 1943-1945.

36 Blanco destacó que en el problema argentino «Armour opina en forma más conciliatoria que Hull». Telegrama de Blanco a Serrato, Washington, 27 de junio de 1944, AHDMREU, Fondo MRE, serie Argentina, caja 4.

37 Para el Departamento de Estado, la Argentina ponía en riesgo la seguridad continental, porque el poder «se halla en manos de fuerzas pro-Nazis» que ayudaban al enemigo totalitario. Muy reservado, Montevideo, 24 de junio de 1944, AHDMREU, Fondo MRE, serie Argentina, caja 4. Los Estados Unidos, además, ampliaron las sanciones económicas hacia la Argentina (Rapoport y Spiguel, 2009, 44-46). No obstante, el gobierno británico si bien se plegó al retiro de su embajador en Buenos Aires no consintió en aplicar un bloqueo comercial, de hecho Winston Churchill señalaba a Roosevelt: «para los ojos británicos, la política norteamericana en la Argentina es sospechosa de estar impulsada menos por el deseo de derrocar a Hitler que por el de extender la influencia de Washington». Rapoport y Spiguel, 2009, 76-77. 
Sur. ${ }^{38}$ La cancillería uruguaya tenía en su poder una copia de una proclama que circulaba en los círculos militares argentinos que marcaba una intención expansionista — «nuestra misión es hacer posible e indiscutible nuestra tutoría»- y para ello proponía los siguientes pasos tácticos: las alianzas eran el primer escalón, donde sostenían que «tenemos ya al Paraguay» para continuar el avance sobre Bolivia y Chile, de manera que a ese cuarteto le resultaría fácil «presionar al Uruguay. Luego las cinco naciones unidas atraerán fácilmente a Brasil». ${ }^{39}$ Con este peligro en la casa de al lado, lo que menos se quería era que la tensión entre Estados Unidos y Argentina se agravara. ${ }^{40}$ Hacia el 30 de junio de 1944 la mayoría de los países habían retirado su embajador, pero el uruguayo permanecía en su puesto. Este hecho era una señal hacia el gobierno argentino, una suerte de seguro para las relaciones binacionales.

En tal sentido, Serrato y Amézaga temían una carrera armamentista regional y la formación de una corriente ultranacionalista y xenófoba. Entonces, Serrato preguntaba a Estados Unidos si no creía «llegado el momento de poner término a esa situación de intranquilidad», con el objetivo de la paz hemisférica. Así pues, proponía utilizar el mecanismo de consulta más que el de las presiones, asimismo, previsor, preguntaba qué sustento podrían ofrecer a Uruguay en caso de guerra. ${ }^{41}$ Estados Unidos confirmó varias veces que Uruguay iba a contar con su apoyo siempre.

Serrato se atrevía a precisar que la solidaridad continental «no puede ser dirección de un solo país sino fruto del acuerdo en procura del bien común», en clara referencia a la orientación cada vez más unilateral que estaba ejerciendo Estados Unidos. Por eso era vital que otro país dejara

38 En La Internacional Justicialista, Zanatta (2013) reconstruye la génesis y la historia del expansionismo peronista. Asimismo Oddone $(2003,39)$ también llama la atención de las pretensiones hegemónicas argentinas.

39 «Camaradas», s/f, ¿1944? (documento que se adjunta a una carta de Martínez Thedy a Serrato, Buenos Aires, 8 de junio de 1944), AHDMREU, Fondo MRE, serie Argentina, caja 4. Independientemente de su veracidad - ya que por aquella época circularon muchos apócrifos- lo interesante es que la cancillería uruguaya lo dio por válido.

40 Telegrama confidencial, Blanco a MREU, Washington, 27 de junio de 1944, AHDMREU, Fondo MRE, serie Argentina, caja 4.

41 Correspondencia muy reservada y confidencial, Serrato a Blanco, Montevideo, 5 de julio de 1944, AHDMREU, Fondo MRE, serie Argentina, caja 4. Este documento por su importancia es reenviado a Blanco otra vez el 20 de julio. Asimismo el gobierno argentino hizo circular un memorándum en el que fundamentaba porqué era inexacta la acusación de filo-nazismo y mostraba evidencias de su solidaridad con las naciones de América y que no admitiría dictados de otros gobiernos, que pudieran menoscabar la dignidad e independencia de su política exterior. Memorándum de la embajada argentina, s/f (por indicios del texto es de principios de julio), AHDMREU, Fondo MRE, serie Argentina, caja 4. 
su embajador, pues si todos los retiraban «Uruguay no podría en ese caso mantenerlo [...] [pues] no puede separarse de la solidaridad americana, apoyada por Gran Bretaña, y menos adoptar actitudes que puedan en lo más mínimo distanciarlo de Estados Unidos». Serrato ratificaba las razones del equilibrismo uruguayo: «La paz de América puede ser alterada, y los preparativos del Brasil y el estado de agitación bélica en que se encuentra la Argentina tiene que inquietar a todos los espíritus uruguayos». Al final el canciller trasmitía su punto de vista estratégico, si bien «el Uruguay no puede ni debe perder el apoyo y la defensa que la solidaridad ha de proporcionarle en un trance semejante. Que solidaridad no implica sumisión sino cooperación, colaboración, discusión pero armonía en los resultados, en interés de la paz». ${ }^{42}$

La última aclaración sobre la definición de solidaridad no debe haber sido muy bien recibida en el Departamento de Estado. El intento de mantener la dignidad nacional del que hizo gala Serrato - un viejo batllista y por tanto pro norteamericano, aunque portador de un moderado nacionalismo- pronto iba a recibir una áspera respuesta norteamericana, en la que harían sentir su nuevo poder hegemónico: no aceptarían fisuras ni excepciones en su bando. Es decir, debía retirarse el embajador que era el único del hemisferio que permanecía en Buenos Aires. El chantaje iba más lejos aun, pues debía «tener en cuenta no solamente "el interés de la solidaridad continental" sino también y especialmente "el propio interés del Uruguay tanto inmediato como a largo plazo" (!)». ${ }^{43}$ La cancillería oriental confirmaba que «todo ello hace pensar que Estados Unidos se inclinaría a adoptar una actitud de recelo, y aun de enojo o enemistad hacia el Uruguay, la cual podría generar, bajo pretextos diversos, medidas contra el país: no enviar petróleo, ni combustible de ningún género, ni elementos económicos básicos, etc. etc.». ${ }^{44}$ La conclusión era que el país permanecería aislado, «perdería la amistad y el apoyo de Estados Unidos y del bloque de las repúblicas americanas, y no tendría, para el caso eventual de un conflicto en el Río de la

42 Documento con la firma manuscrita de Serrato, probablemente fechado entre el 7 y 9 de julio de 1944, AHDMREU, Fondo MRE, serie Argentina, caja 4.

43 Subrayado y con signo de admiración en el original. Memorándum, Montevideo, 13 de julio de 1944, firmado por Nelson García Serrato y otro miembro de la cancillería cuya firma no reconocemos, AHDMREU, Fondo MRE, serie Argentina, caja 4. En el documento se relata que la nota norteamericana «sugiere conexiones con la prédica que desarrollan hace un mes, e intensifican en estos días, "El Día" y "El País". Es por otra parte, la posición radical de representantes de fuertes sectores mayoritarios en el cuadro político nacional».

44 Idem. 
Plata, ninguna garantía para su independencia». ${ }^{45}$ Uruguay, entonces, «solo podría aspirar a la consideración de Argentina», lo que no era una garantía. Y si no se sumaba al boicot quedaría implicado al lado de un gobierno anti popular que seguramente caería.

Washington no toleraría disidencias que pudieran «comprometer sus sistemas de seguridad», asimismo era previsible «que se asigne el Río de la Plata un considerable valor estratégico en la futura evolución de la guerra en el sistema internacional y político del futuro». ${ }^{46}$ Enemistarse con la nueva potencia emergente, sustituta del imperio británico en la región, no era un buen negocio para el gobierno de Amézaga. Finalmente, se llamó en consulta al embajador Martínez Thedy ${ }^{47}$ Ahora, los retiros colectivos de los jefes de misión serían eficientes si eran «un primer paso en un proceso de coacciones progresivas y rápidas, capaces de determinar, cuando menos, un cambio rápido de orientación en el gobierno de Farrell». ${ }^{48}$ Uruguay quedaba en el medio de un juego político complicado, arrinconado por los contendientes que buscaban la mínima ocasión para intentar influir en su derrotero internacional.

Veamos los hechos de setiembre de 1944, como muestra. Seguro de su rol imperial, Estados Unidos propuso al Uruguay realizar «conversaciones exploratorias y no oficiales» con el fin de estudiar temas de cooperación militar. Para ello, el Departamento de Defensa estaría dispuesto a enviar oficiales para que tuvieran reuniones con militares uruguayos. Así pues había echado a andar su sistema interamericano de defensa a toda velocidad,

45 Idem.

46 Idem.

47 Idem. En el memorándum citado se adjunta una nota en la que dice que el 10 de julio se había resuelto llamar al embajador Martínez Thedy, información que fue trasmitida personalmente al implicado y al embajador de los Estados Unidos en Montevideo, William Dawson, por lo cual no había sido conocida por otros miembros de la cancillería.

48 Memorándum, Montevideo, s/f (probablemente finales de julio de 1944), AHDMREU, Fondo MRE, serie Argentina, caja 4. Asimismo, en un folleto del grupo de derecha argentino Alianza Libertadora Nacionalista agradecían la resolución del directorio del Partido Nacional contra la política «intervencionista» en la Argentina. Folleto «7 senadores y 23 diputados uruguayos afirman la hermandad rioplatense», Montevideo, 31 de julio de 1944, AHDMREU, Fondo MRE, serie Argentina, caja 4. La posición del herrerismo es radicalmente opuesta a la de Luis Batlle Berres quien compartía las posiciones del gobierno de turno. Batlle Berres estaba preocupado por las «medidas militares poco amistosas» tomadas por el gobierno de Buenos Aires en las fronteras del río Uruguay y por «el clima inamistoso que está creando en su pueblo contra nosotros». Por lo cual consideraba que la unidad con el pueblo argentino subsistía, y eso significaba que no apoyarían a un gobierno «que ni representa al pueblo, ni atiende sus aspiraciones, ni cuida los intereses de América, ni sabe ser respetuoso para con sus vecinos y se mueve con veleidades y aspiraciones de dominio sudamericano». Carta de Batlle Berres al chileno Pedro Castalblanco, Montevideo, 24 de julio de 1944, Archivo General de la Nación Uruguay (AGNU), Fondo Luis Batlle Berres (LBB). 
estaban seguros que de esta manera se «asentarían los cimientos para una colaboración fructífera». ${ }^{49} \mathrm{O}$ sea, el Pentágono pasaría a abastecer y entrenar a los militares uruguayos en el nuevo orden mundial. Serrato no estaba de acuerdo con el punto. Si bien no veía inconveniente en que se efectuaran las reuniones «exploratorias y no oficiales» aclaraba, estas debían ser no entre simples oficiales sino «entre los Estados Mayores de los respectivos países». El ministro sugirió «la firma de un gran pacto americano de paz, seguridad y mutua protección» que garantizara la integridad territorial, el respeto de los derechos y el arreglo pacífico de las controversias. ${ }^{50}$

Lo llamativo es que la propuesta de Serrato recibió una respuesta del secretario de Estado. En la nueva realidad hemisférica que se avecinaba Uruguay iba a ser, si no era ya, una pieza importante. Hull no veía mal que se estableciera un pacto americano en el futuro, pero que para ejecutar «esa hermosa idea» era necesario que toda América estuviera unida, cosa que Argentina evitaba realizar. Por tanto el pacto recomendado por Serrato no se desarrollaría hasta «que varíen por completo las circunstancias». ${ }^{51}$ Al final Hull se mostró dispuesto a enviar a Uruguay «los armamentos necesarios para su seguridad interna y externa», por lo que apresuraría las consultas sobre el tema con las autoridades competentes. ${ }^{52}$ Argentina, en la misma época, tenía otra razón para estar molesta con su vecino: las emisiones radiales, publicaciones y panfletos que se realizaban contra la dictadura desde Montevideo por exiliados, una protesta que se repetirá hasta $1955 .^{53}$

49 Muy confidencial, correspondencia de Serrato a Blanco, Montevideo, 5 de septiembre de 1944, AHDMREU, Fondo MRE, serie Argentina, caja 4. (Se transcriben las notas intercambiadas con el embajador norteamericano en Montevideo, William Dawson).

50 Idem. La respuesta del canciller uruguayo buscaba esquivar la injerencia norteamericana, una manera diplomática de señalar que una cuestión de este calibre no se resolvía entre «oficiales» sino entre Estados Mayores, lo que Estados Unidos aun en guerra no iba a poder hacer.

51 Carta (confidencial) de Blanco a Serrato, 22 de septiembre de 1944, AHDMREU, Fondo MRE, serie Argentina, caja 4. En el documento se transcriben las conversaciones con el secretario de Estado norteamericano.

52 Idem. «Hay en los medios militares alguna inquietud y queja por la forma como Estados Unidos envía los armamentos y equipos para nuestro Ejército. Dicen que son incompletos o insuficientes, y que ante una agresión de la Argentina, por ejemplo, no podría resistirse sino breves momentos. Ruéguele al señor Hull quiera llevar adelante su promesa de influir para que el Uruguay obtenga los armamentos necesarios para su seguridad interna y externa». Carta de Serrato a Blanco, Montevideo, 6 de octubre de 1944, AHDMREU, Fondo MRE, serie Argentina, caja 4.

53 Por ejemplo, Embajada argentina en Montevideo, nota de protesta del 18 de septiembre de 1944, AHDMREU, Fondo MRE, serie Argentina, caja 4. Entre las organizaciones pluripartidistas de exiliados destacan Asociación de Mayo y Patria Libre. Sobre la génesis del antiperonismo y el exilio en Montevideo, García Sebastiani, 2005, 44-48. 


\section{5 y el Uruguay: el año en que todo cambió}

El mundo más justo «y menos imperialista» que había soñado Serrato iba a ser, en realidad, otro muy distinto marcado por «el choque de intereses entre las tres grandes potencias vencedoras que no ha de tardar en producirse, por más que todas ellas deseen evitarlo». ${ }^{54}$ En ese escenario que preveía la Guerra Fría, ¿qué posición debía tomar el Uruguay en la convulsionada región? Asimismo, la relación con Estados Unidos basada en «la buena vecindad ${ }^{55}$ ¿hasta cuándo duraría?, ¿continuaría?, ¿había sido acertada? $\mathrm{Al}$ fin y al cabo varios políticos norteamericanos sostenían que esa política de Roosevelt había habilitado la existencia de regímenes como el argentino. Hacia 1945 la construcción del nuevo mundo era, para los diplomáticos y para las sociedades en general, algo brumoso e imprevisible.

Había un consenso general en América Latina de que Argentina, que no había participado en la Conferencia Interamericana sobre los problemas de la Guerra y la Paz, reunida en el castillo de Chapultepec entre el 21 de febrero y 8 de marzo, debía reincorporarse cuanto antes y de la manera menos traumática posible al concierto de las naciones. ${ }^{56}$ No obstante, se le ofreció la posibilidad de firmar el Acta de Chapultepec y declarar la guerra al Eje para así poder ingresar a la ONU. La embajada uruguaya en Buenos Aires informaba sobre desacuerdos en la interna militar argentina, entre un sector nacionalista agresivo y nazi a ultranza y otro oportunista, que parecía con probabilidades de éxito. ${ }^{57}$ No aceptar lo acordado en México implicaba aislarse completamente y, peor aun, quedar fuera «de las deliberaciones de postguerra». Para Azarola Gil, consejero de la embajada, la declaración de beligerancia a Alemania y Japón era el punto central del debate, que se encontraba en un callejón sin salida. ${ }^{58}$

54 Carta de Serrato a Blanco, Montevideo, 6 de octubre de 1944, AHDMREU, Fondo MRE, serie Argentina, caja 4.

55 Sobre la política norteamericana de «buena vecindad» ver Rapoport y Spiguel, 2009, $20-22$.

56 Ya antes de la conferencia varias naciones americanas habían insistido en que la Argentina no podía quedar excluida: Telegrama de Marques Castro a MREU, México, 10 de noviembre de 1944 y carta personal y confidencial de Blanco a Serrato, Washington, 10 de diciembre de 1944, AHDMREU, Fondo MRE, serie Argentina, caja 4, carpeta Edelmiro Farrell. Blanco expresaba la necesidad de acabar el conflicto con la Argentina, pero que ello no podía significar el abandono de la «fidelidad a las naciones unidas y asociadas».

57 Azarola Gil a MREU, Buenos Aires, 19 y 21 de febrero de 1945, AHDMREU, Fondo Legaciones y Embajadas, sección Argentina, caja 1, 1943-1945.

58 De hecho, Perón consideraba que la vuelta a la democracia era más factible que la declaración de guerra. Azarola Gil a MREU, Buenos Aires, 17 y 19 de marzo de 1945, AHDMREU, Fondo Legaciones y Embajadas, sección Argentina, caja 1, 1943-1945, carpeta 29. 
Finalmente el nacionalista y altivo gobierno de Farrell-Perón firmó el Acta de Chapultepec y le declaró la guerra al Eje, visto como un formalismo, no auténtico. ${ }^{59}$ Para la diplomacia uruguaya la contradicción más grave, lo que «resultaba incomprensible o incompatible [era declarar] la guerra contra las potencias totalitarias mientras la estructura actual de la Nación argentina es igualmente totalitaria». ${ }^{60}$

Los embajadores retornaron a Buenos Aires, el uruguayo, Martínez Thedy, tomó posesión de su cargo el 10 de abril, y el 19 de mayo de 1945 arribó el nuevo jefe de misión norteamericano, Spruille Braden, y ya nada fue lo mismo. La distensión se hizo cada vez mayor, especialmente cuando a principios de junio se puso en libertad a los presos políticos y se permitió la vuelta de los exiliados. Braden se involucró en la campaña política a favor del retorno a la democracia. La embajada y el gobierno uruguayo fueron sumamente prudentes ante sus embates a la dictadura militar. ${ }^{61}$

En los meses siguientes, los informes diplomáticos uruguayos abonaban las esperanzas sobre la crisis definitiva del régimen y la caída de Perón. ${ }^{62}$ Un síntoma de esa inestabilidad fue la renuncia del embajador argentino en Uruguay, Dr. Alberto Uriburu, por discrepancias con su gobierno, cosa que se encargó de publicar en los diarios de Buenos Aires. ${ }^{63}$ El gobierno de Amézaga, sus diplomáticos y los medios de comunicación favorables a los «opositores democráticos» argentinos no comprendieron la metamorfosis profunda

59 Azarola Gil a MREU, Buenos Aires, 26 de marzo de 1945, AHDMREU, Fondo Legaciones y Embajadas, sección Argentina, caja 1, 1943-1945. Asimismo, la aceptación del Acta de Chapultepec se hizo evitando toda alusión a la defensa de la democracia. Y de hecho se declaró la guerra a Alemania «en tanto aliada de Japón». Argentina y Perón seguían siendo vecinos bajo sospecha.

60 Azarola Gil a Serrato, Buenos Aires, 4 de abril de 1945, AHDMREU, Fondo Legaciones y Embajadas, sección Argentina, caja 1, 1943-1945, carpeta 29. El consejero de la embajada estaba convencido de la «desintegración del gobierno militar».

61 Telegrama de Martínez Thedy a Serrato, Buenos Aires, 31 de julio de 1945, AHDMREU, Fondo Legaciones y Embajadas, sección Argentina, caja 1, 1943-1945. Se informaba que el cuerpo diplomático acreditado en Buenos Aires convocaba a una cena de desagravio en honor a Braden, víctima de la «difusión de impresos injuriosos». Además estaban elaborando una nota para enviar al gobierno de Farrell. Martínez Thedy solicitó consultar al gobierno y sugería «que tenía dudas sobre la conveniencia de enviar una nota al gobierno argentino, podría crearle una situación molesta y prestarse a interpretaciones enojosas contrarias al verdadero móvil de la actitud proyectada».

62 Por ejemplo: Correspondencia de Martínez Thedy a Serrato, Buenos Aires, 23 de agosto de 1945, AHDMREU, Fondo Legaciones y Embajadas, sección Argentina, caja 1, 1943-1945.

63 Correspondencia de Martínez Thedy a Serrato, 8 de setiembre de 1945, AHDMREU, Fondo MRE, serie Argentina, caja 5. Poco después el embajador uruguayo informaba que «numerosos oficiales almirantes y capitanes de navío, en retiro, acaban de expresar en forma pública su pensamiento sobre el actual momento político argentino» en clave opositora. Correspondencia de Martínez Thedy a Serrato, Buenos Aires, 24 de septiembre de 1945, AHDMREU, Fondo Legaciones y Embajadas, sección Argentina, caja 1, 1943-1945. 
que se había producido en la sociedad hermana, o sea, se les escapó esa otra Argentina que estaba a punto de aparecer. Quiso la casualidad que mientras se procesaba ese giro histórico, en Uruguay —el 4 de octubre de 1945- asumía un nuevo ministro de Relaciones Exteriores, Eduardo Rodríguez Larreta, quien fue un acérrimo enemigo de la naciente Argentina peronista.

$\mathrm{Si}$ bien se ofrecieron argumentos menores para el cambio ministerial — «el Ing. José Serrato había anunciado su voluntad de retirarse de la actividad política»— ${ }^{64}$ no puede dejar de llamar la atención que ocurriera justo en ese momento y que los personajes presentaran perfiles distintos. Serrato había buscado una política de equilibrio con Argentina y al mismo tiempo mantuvo la alianza con los norteamericanos, y trató de no terminar en una situación de sumisión, protegiendo el decoro internacional de su país y la seguridad de sus fronteras. Su oposición a la existencia del Consejo de Seguridad de la ONU, en la conferencia de San Francisco, por entenderlo no democrático, le valió duras críticas de los aliadófilos en el Uruguay y seguramente no cayó bien en el Departamento de Estado. A su vez, sus posiciones que reflejaban el típico moderado nacionalismo batllista, no tenían lugar en la nueva realidad que se avecinaba. Tal vez Amézaga supuso que necesitaba de una personalidad más vehemente que alineara al Uruguay en el escenario de la postguerra en la región. Esa fue la función de Rodríguez Larreta, especialmente en las relaciones con los Estados Unidos. Por algo diría que apenas había asumido había tenido una entrevista urgente con el embajador norteamericano. ${ }^{65}$

El 8 de octubre de 1945 un inquieto Martínez Thedy informaba que en Buenos Aires «circulan versiones sobre grave situación militar» que se estaba procesando en Campo de Mayo. Todo le hacía prever que «están produciéndose acontecimientos importantes». ${ }^{66}$ Farrell presionado por la asamblea de oficiales acordó que Perón renunciaría a todos sus cargos. ${ }^{67}$

A pesar de los cambios dramáticos que se estaban desarrollando en la Argentina y que podían prever una salida hacia la democracia, los Estados Unidos proseguían su trabajo diplomático para aislar al país, como

64 Casal, 1997, 15

65 Las cuestiones tratadas entre Rodríguez Larreta y el embajador norteamericano en Montevideo fueron dos: la suspensión de la Conferencia de Río y la de «iniciar consultas sobre la situación argentina». nota del MREU-Secretaría General, Montevideo, 15 de octubre de 1945, AHDMREU, Fondo MRE, serie Argentina, caja 3.

66 Telegrama de Martínez Thedy a Serrato, Buenos Aires, 8 de octubre de 1945, AHDMREU, Fondo Legaciones y Embajadas, sección Argentina, caja 1, 1943-1945.

67 Sobre la crisis de octubre de 1945 y el triunfo de Perón, se recomienda: Torre, 2006, 102-125; Luna, 1984, 209-358 y James, 1990, 46-50. 
si la dictadura de Farrell fuera un régimen poderoso y estable. Mientras Martínez Thedy comunicaba a la cancillería su impresión de que «se tiende a cierta normalidad», ${ }^{68}$ llegaba a Montevideo un memorándum explosivo del Departamento de Estado solicitando la opinión sobre qué hacer con Argentina. El documento volvía a las valoraciones sobre el totalitarismo, el nazi-fascismo y los incumplimientos argentinos al respecto, pero lo que realmente importa es que ponía en evaluación cinco puntos sobre la manera de actuar con el vecino. Es decir, se quería saber, en primer lugar, si Uruguay estaba de acuerdo en que Naciones Unidas iniciara alguna acción. El segundo punto proponía nombrar una comisión «compuesta por 4 o $5 \mathrm{Mi}$ nistros de Relaciones Exteriores» que informaría sobre el no cumplimiento del gobierno de Buenos Aires con los compromisos interamericanos. Una tercera posibilidad era no tomar una medida unilateral hasta que no se terminaran las consultas. En cuarto lugar entendían que estas «se limiten a la consideración del no cumplimiento por el gobierno argentino con los compromisos contraídos bajo las resoluciones de México» o sea el Acta de Chapultepec. Y como quinta opción ofrecían que se cambien informaciones sobre las «pruebas de dicho no cumplimiento». ${ }^{69}$

La consulta al Uruguay, a pesar de haber sido hecha ya a diecisiete países, tomaba características especiales por su posición geoestratégica. Quizá esa fue la razón por la cual Rodríguez Larreta el 15 de octubre — nótese la fecha, a mitad de camino entre la caída de Perón y a dos días de su regresodecidió consultar al espectro político gobernante o cercano al gobierno. Así, fueron convocados a la cancillería batllistas, blancos independientes y cívicos para recabar sus opiniones sobre la propuesta norteamericana. Las transcripciones de estas discusiones son un aporte valioso para el análisis histórico, pues permiten conocer de primera mano la actitud y los puntos de vista de los dirigentes uruguayos sobre la crítica situación del otro lado del Plata. ${ }^{70}$ En cierta forma, el hecho de que Estados Unidos realizara esta

68 Correspondencia de Martínez Thedy a Rodríguez Larreta, Buenos Aires, 10 de octubre de 1945, AHDMREU, Fondo Legaciones y Embajadas, sección Argentina, caja 1, 1943-1945. En la misma caja hay varios telegramas del 13 de octubre que refieren a la situación política argentina.

69 Muy reservado, Montevideo, 11 de octubre de 1945, AHDMREU, Fondo MRE, serie Uruguay, caja 22, carpeta 21. En la caja también se encuentra el documento en inglés procedente de Washington, fechado el 10 de octubre y firmado por Byrnes.

70 Nota del MREU-Secretaría General, Montevideo, 15 de octubre de 1945, AHDMREU, Fondo MRE, serie Argentina, caja 3. El documento es la transcripción de lo debatido en la reunión celebrada en la cancillería con los siguientes asistentes: Juan Andrés Ramírez, Jacobo Varela Acevedo, José A. Quadros, Cesar Batlle Pacheco, Alberto Domínguez Cámpora, Héctor Paysee Reyes, Cyro Giambruno y Dardo Regules. También estuvo presente el asesor letrado del Ministerio, Gilberto Pratt de María. 
consulta implicaba el alto concepto que tenía de su pequeño aliado, y tal vez en estos intercambios se estaba incubando la Doctrina Larreta.

Luego de un largo intercambio los dirigentes políticos concluyeron que lo mejor era esperar a que se definiera la actualidad política argentina, en plena efervescencia. Sin embargo es interesante subrayar la perspectiva que presentó el canciller: «la cuestión no solo [es] de nuestra posición respecto al momento actual de la Argentina, sino también cuál debe ser la actitud de América frente a los gobiernos de la misma índole que existan o se creen en el futuro dentro del continente. Sería un juicio permanente de extraordinaria trascendencia», ${ }^{71}$ un esbozo de la doctrina intervencionista que lo tendría a él como padre. Si bien todos los concurrentes admitían la gravedad del momento, y que la Argentina era un régimen totalitario y peligroso para el Uruguay, finalmente la respuesta a Estados Unidos buscó la mayor coincidencia con la potencial posición que asumiría el Departamento de Estado. Para Rodríguez Larreta era muy grave que en Argentina hubiera capitales nazis, o actividades nazis de cualquier tipo. En consecuencia comunicaba a sus aliados del norte un concepto que guiaría la doctrina que presentaría poco después:

Quiero dejar establecido que, acordando todo su significado e importancia el principio de no intervención, [...] no creo que pueda extenderse hasta amparar ilimitadamente la notoria y reiterada violación por alguna república de los derechos más elementales del hombre y del ciudadano y el incumplimiento de los compromisos libremente contraídos acerca de los deberes externos e internos de un Estado que lo acreditan para actuar en la convivencia internacional. ${ }^{72}$

El ministro terminaba afirmando su famosa tesis para la política americana, «la del paralelismo entre la democracia y la paz». ${ }^{73} \mathrm{O}$ sea, estaba a favor de limitar el principio de no intervención cuando se violaran derechos fundamentales, por supuesto que no definía quién evaluaría la existencia de esas violaciones. La coyuntura aconsejaba esperar que el escenario argentino se despejara. De manera que recomendaba a su aliado del norte no intervenir «por ahora».

La embajada uruguaya el 17 de octubre destacaba que la «preocupación principal» era «la constitución del gabinete», por las sucesivas renuncias ministeriales. Sin embargo no dejaba de advertir que «se han producido

71 Idem.

72 Idem.

73 Documento confidencial, Montevideo, 19 de octubre de 1945, AHDMREU, Fondo MRE, serie Uruguay, caja 22. 
manifestaciones callejeras» donde «predominan elementos procedentes de los suburbios de la Capital Federal, cuyas expresiones los revelan como adictos a la persona y tendencias sociales del ex Vicepresidente de la República, Coronel Juan D. Perón». No había obreros, ni siquiera personas, la muchedumbre en las calles eran «elementos»y, para peor, de los suburbios. ${ }^{74}$ Esta primera interpretación del acontecimiento fue similar a la que hizo el espectro político antiperonista del Uruguay. A media tarde la avalancha humana que avanzó sobre Buenos Aires cambió la percepción del asombrado embajador. De urgencia, en un telegrama cifrado, Martínez Thedy, en un tono inusual, describía que «prodúcese agitación elementos obreros partidarios del Coronel Perón recorren desde primeras horas calles de Buenos Aires con vehementes demostraciones a su favor. Son grupos [que] proceden de Avellaneda y otras zonas industriales de la Provincia, especialmente las que corresponden a Frigoríficos $[s i c] \gg .{ }^{75}$ Ya no eran simples elementos de los suburbios, ahora eran obreros principalmente de un rubro fundamental de la economía, la industria frigorífica, que venían a reclamar por sus derechos y por la libertad de su líder. La huelga convocada para el 18 — «sin saberse el grado de éxito que tendrá»— era el reflejo del «aspecto tumultuoso [que] va adquiriendo aquella agitación». ${ }^{76}$

La Argentina vivió el gran giro histórico aquel 17 de octubre, cuando los trabajadores y los sectores populares entraron a la fuerza, si se quiere, a integrar el país, y las clases medias, los intelectuales y el cuerpo diplomático solo vieron «hordas» y no a una sociedad que defendía sus derechos. Por ejemplo, Roberto Ibáñez, dirigente del Partido Socialista uruguayo, hombre de letras comprometido con las luchas sociales en su país, estaba casualmente en Buenos Aires ese día. Su descripción de los hechos no desentonaba con la de Martínez Thedy y representaba la interpretación promedio que tuvo el antiperonismo uruguayo: «Perón no es un mito. Es, por desgracia, una realidad que costará disminuir y disolver». En su discurso, Perón «Argentinizó a la manera de Rosas; no de Moreno, San Martín, Rivadavia, Sarmiento». El fenómeno social que tenía ante sus ojos era descrito de la siguiente forma: «presumen de obreros. Y muchos, por desgracia, lo son; pero son, al par, los infaltables rompehuelgas; los trabajadores desaprensivos y

74 Correspondencia de Martínez Thedy a Rodríguez Larreta, Buenos Aires, 17 de octubre de 1945, AHDMREU, Fondo Legaciones y Embajadas, sección Argentina, caja 1, 1943-1945.

75 Telegrama de Martínez Thedy a Rodríguez Larreta, Buenos Aires, de 17 de octubre de 1945, AHDMREU, Fondo Legaciones y Embajadas, sección Argentina, caja 1, 1943-1945, Buenos Aires.

76 Idem. 
egoístas, sin conciencia de clase». Ibáñez, con mucha lucidez y sin dejar de lado el desdén, veía las causas sociales del hecho: «Favorecido por el atraso de la legislación obrera en la Argentina, recurrió a burdas concesiones, intentando sustituir la ley. Pero las dádivas de los déspotas son siempre revocables porque se apoyan en la arbitrariedad». Lo que vio en Plaza de Mayo no era «el verdadero pueblo», ese fue el «que desfiló conmovido en la gran Marcha de la Libertad. El pueblo encarnado en las mujeres que se congregaron en las calles de Buenos Aires desafiando la barbarie policial; los obreros auténticos, inmunes al soborno y a la mentira». ${ }^{77}$

El triunfo del peronismo en 1945 encendió las alarmas desde Washington hasta Montevideo. ${ }^{78}$ Se había comprobado que no era solo una imposición militar sino que contaba con un innegable apoyo popular. En definitiva, ¿cómo operar para terminar con el único foco «totalitario» del continente? En ese contexto, el Uruguay y su canciller tuvieron un papel clave en el concierto regional y en la estrategia de Estados Unidos para enfrentar al peronismo en sus inicios. La doctrina que llevaría su nombre, en realidad fue «sugerida», digámoslo así, por el Departamento de Estado y discutida en Montevideo, en absoluta reserva, con importantes dirigentes políticos el 29 de octubre de $1945 .{ }^{79}$ Rodríguez Larreta leyó una nota «sumamente reservada» del Departamento de Estado donde se le solicitaba a Uruguay asumir determinadas actitudes dirigidas hacia Argentina. ${ }^{80}$ César

77 «El peligro nazi en la Argentina», El Sol, 9 de noviembre de 1945. El análisis final de Ibáñez estaba en sintonía con las concepciones antiperonistas clásicas: «El Coronel es la versión criolla, el modelo 1945 de Mussolini y Hitler, ya sin sombra en Europa. Usa métodos de sus liquidados arquetipos: el nacionalismo ramplón e irresponsable, la prepotencia sistemática, el histrionismo espectacular, la baja demagogia, el desdén por la cultura». En cuanto a la marcha de la libertad fue una significativa manifestación de la oposición democrática realizada el 19 de septiembre de 1945. El libro de Spinelli (2005) reconstruye y complejiza la trayectoria histórica del antiperonismo y las imágenes construidas sobre el peronismo. En relación con nuestro objeto de estudio, véanse páginas 140-150, 154-58, 180 $81,184-85$ y $240-44$. Una obra que recoge las miradas nacionales e internacionales sobre el peronismo: Rein y Panella, 2008.

78 Telegrama de Martínez Thedy a Rodríguez Larreta, Buenos Aires, 18 de octubre de 1945, AHDMREU, Fondo Legaciones y Embajadas, sección Argentina, caja 1, 1943-1945. El embajador dio cuenta de la llegada de diversos refugiados a la embajada uruguaya y de pedidos de asilo.

79 A la reunión en cancillería concurrieron: Eduardo Rodríguez Larreta y Martín Aguirre, como ministro y sub secretario, y los siguientes políticos: Juan Andrés Ramírez, Jacobo Varela Acevedo, César Batlle Pacheco, Dardo Regules, Héctor Payssé Reyes, Alberto Domínguez Cámpora, Cyro Giambruno y José A. Quadros. Nota confidencial, Montevideo, 29 de octubre de 1945, AHDMREU, Fondo MRE, serie Argentina, caja 3.

80 La nota norteamericana no ha sido encontrada aun, pero por el debate que se desarrolló pudimos inferir que se le solicitaba al Uruguay realizar una declaración doctrinaria que apuntara a la Argentina, que implicara relativizar el principio de no intervención en contraposición al principio de democracia y paz. 
Batlle Pacheco fue quizá el más vehemente defensor de la propuesta norteamericana. Veía a Argentina, ahora más que nunca, como un régimen nazi, por tanto consideró que:

no debemos apartarnos de la política de colaboración con los Estados Unidos. Si lo hiciéramos, caeríamos fatalmente en la órbita de ese vecino que soporta un régimen nazista y nuestra democracia sucumbiría. Debemos proceder con valor y disponernos a iniciar el camino hacia la acción colectiva frente a la Argentina. Si Estados Unidos nos propone ser los iniciadores de esa acción, es porque somos el único país en condiciones de hacerlo, porque somos la única democracia. Por lo demás, ese gran país que es Estados Unidos nos ofrece todo su apoyo. ${ }^{81}$

Y más adelante concluyó: «el poder irresistible de Estados Unidos recurre a nuestro pequeño poder moral». Rodríguez Larreta precisó que Washington solicitaba que «extendamos los principios de la nota ya conocida», a su vez quería convertirla en «una declaración continental». ${ }^{82}$ Con matices, todos los participantes estuvieron de acuerdo en que Uruguay debía tomar la iniciativa con valentía y con el apoyo de Estados Unidos. Solo faltaba fijar la oportunidad en que la nota enviada por el ministro a Washington el 19 de octubre se transformara en doctrina.

El 20 de noviembre de 1945, el Departamento de Estado hizo llegar al Uruguay un «repartido confidencial» y aclaraba que «no deberá ser publicado, citado o utilizado de ninguna forma» ${ }^{83} \mathrm{El}$ texto era la transcripción de un discurso de Ellis O. Briggs, Director de la Oficina de Asuntos de las Repúblicas Americanas, donde se trazaba la línea a seguir en la Conferencia de Río. Era, básicamente, el libreto general sobre el armado del sistema panamericano. Para el objeto de nuestro trabajo nos importan dos puntos. En primer lugar, anunciaba la creación de lo que luego sería el TIAR, y lo presentaba como algo ya prefabricado, como «el primer instrumento inter-americano de este carácter que nuestro gobierno ha estado preparado para ajustar» el que se enviaría a todos los países americanos «para su previa consideración». ${ }^{84} \mathrm{El}$ segundo punto clave fue una precisión al principio de no intervención, que: «no prohíbe a ningún gobierno

81 Idem.

82 Nota confidencial, Montevideo, 29 de octubre de 1945, AHDMREU, Fondo MRE, serie Argentina, caja 3.

83 Confidencial, Departamento de Estado, Montevideo, 20 de noviembre de 1945, AHDMREU, Fondo MREU, serie Uruguay, caja 22. En el documento traducido se aclaraba que fue un mensaje dado por Briggs en la Universidad de Pennsylvania.

84 Idem. 
aconsejarse con otros sobre la situación existente en una o más naciones de nuestro hemisferio, o actuar con otros gobiernos para corregir condiciones que perjudicarían la seguridad o el bienestar de las Américas». ${ }^{85}$ La nueva posición estadounidense «no es intervención; es el ejercicio legítimo de iniciativa colectiva». ${ }^{86}$ Finalmente, Briggs aclaraba: ninguna organización internacional podría funcionar sin estos intercambios «sin la oportunidad de exponer sus opiniones [...] o de buscar la acción multilateral responsable ante una decisión acordada a continuación de la discusión». ${ }^{87}$ Y para esta acción multilateral no hacía falta la unanimidad del continente, concepto este al que había que cambiar por no ser realista: «La política de no intervención no implica [...] la aprobación de la tiranía local». ${ }^{88}$ A los tres días de recibido este documento se dio a conocer la Doctrina Larreta.

El 23 de noviembre, Rodríguez Larreta hizo pública una extensa nota que envió a los cancilleres de América y que había sido votada en el consejo de ministros por unanimidad. O sea, era una posición oficial del gobierno uruguayo. En ella se reafirmaba el vínculo entre democracia y paz, su núcleo central era la propuesta de mantener el principio de no intervención «pero armonizarlo con otros cuya vigencia adquiere importancia fundamental para la conservación de la paz y la seguridad internacionales». ${ }^{89} \mathrm{En}$ concreto, la lucha contra el nazi-fascismo no fue un hecho aislado en un continente, también se daba a escala planetaria y, como «los conflictos no pueden ser aislados, ni pueden subsistir indefinidamente», hay derecho a ponerles término. En esencia, «la no intervención no es el escudo atrás del cual se perpetra el atentado, se viola el derecho, se ampara a los agentes y fuerzas del Eje, y se burlan los compromisos contraídos»..$^{0}$ En definitiva, «ante sucesos notorios» debería darse «un pronunciamiento colectivo multilateral [...] sea por medio de una Comisión dictaminante, sea por una consulta expresa, sea incorporando el tema a la proyectada conferencia de

85 Idem.

86 Idem.

87 Idem.

88 Idem.

89 Casal, 1997, 29. También en: Carta de Rodríguez Larreta a Javier Correa, ministro de Relaciones Exteriores de Perú, Montevideo, 21 de noviembre de 1945, AHDMREU, Fondo MRE, serie Uruguay, caja 22.

90 Idem, p. 5. «La no intervención no puede transformarse en el derecho de invocar un principio para violar impunemente todos los otros. No debe considerarse, entonces, que una acción colectiva multilateral ejercida con total desinterés por las demás repúblicas del continente [...] [para] el simple restablecimiento de lo que es esencial [...] y que se ejerce en beneficio de todos». 
Río de Janeiro». ${ }^{91}$ El objetivo era habilitar la intervención en Argentina con un respaldo jurídico internacional..$^{92}$

La doctrina contó con el apoyo relativo de los países de América, con la excepción de Argentina, Colombia, Ecuador, El Salvador y Haití que rechazaron íntegramente la propuesta. Paraguay y Bolivia no se pronunciaron. Mientras varios de los países consultados ponían alguna objeción al documento, los Estados Unidos fueron enfáticos: «completa adhesión». ${ }^{93}$

Las elecciones se realizarían el 24 de febrero de 1946 y el bloque opositor continental abrigaba la esperanza del triunfo de la fórmula electoral de la Unión Democrática (en adelante UD), José Tamborini-Enrique Mosca, concebida como una alianza antifascista. ${ }^{94}$ Uruguay recibió varias protestas del Palacio San Martín por el tono y estilo de las audiciones radiales. Quizá el mejor ejemplo de lo anterior sean las de Luis Batlle Berres en Ariel y su radical simpatía a la UD, así como su rechazo casi visceral al peronismo y a sus aliados uruguayos, el herrerismo y su diario El Debate..$^{95}$ En los programas se refería a los seguidores de la candidatura de Perón como «bandas», «turbas bárbaras», «pistoleros» o «matones». De alguna manera, era el enfrentamiento entre la barbarie y la moralidad del pueblo argentino: «Ponen en peligro no solo la tranquilidad de Buenos Aires, sino que desprestigian en tal forma la educación civilista de la Argentina». ${ }^{96}$ La campaña electoral se presentaba a favor o en contra de la democracia; el escenario no era solo el argentino sino el continental, estaba en juego la paz y la tranquilidad de los países vecinos. La elección se reducía a: Tamborini o Hitler. ${ }^{97}$ A continuación llamaremos la atención de cuál era la opinión del futuro presidente

91 Idem.

92 En su editorial, El Debate fue claro: «La nota del Ministro de Relaciones Exteriores circulada a las Cancillerías de América, tiene un único objetivo: procurar la intervención extraña en la política interna de la Argentina» («La inconciencia de una actitud», El Debate, 25 de noviembre de 1945). Una síntesis sobre el pensamiento de Herrera sobre el deber de la política internacional del Uruguay en Zubillaga, 1976, 88-137.

93 AHDMREU, Fondo MRE, serie Argentina, caja 3, s/f, ¿Fines de 1945? Ver también en la caja citada el documento fechado en Montevideo el 11 de enero de 1946.

94 La UD estaba integrada por radicales, socialistas, comunistas y demócratas progresistas, contó con el aval de los grandes medios de comunicación, la Sociedad Rural, la Unión Industrial Argentina, el Jockey Club, entre otros. Sobre la gestación de la coalición electoral de la UD véase García Sebastiani, 2005, 25 y 48-63 y en relación a la campaña electoral, véase Ruiz Jiménez, 2006, 141-151.

95 «Comentarios de política internacional. Sr. Luis Batlle Berres», AGNU, Fondo LBB, caja 21. En la caja se encuentran las desgravaciones de los programas de radio Ariel de las 8.15 hs. de los siguientes días: 10, 12, 14, 15, 16, 17, 20 y 21 de febrero de 1946.

96 «Situación política en la Argentina», 12 de febrero de 1946, p. 4, AGNU, Fondo LBB, caja 21.

97 Programa del 20 de febrero de 1946, AGNU, Fondo LBB, caja 21. 
del Uruguay sobre la política esperable del militar argentino, texto que dice mucho sobre el posterior y conflictivo relacionamiento bilateral:

\begin{abstract}
Perón no es un problema solo argentino, porque Perón desde el gobierno va a imponer un terror y una violencia, y va a realizar una gestión pública con tales caracteres, que sin duda pondrá en peligro la tranquilidad y la paz americana [...] que va a tener oprimido al pueblo, que va a continuar una política de agresión, que se va a hallar rodeado por hombres que no son respetuosos de nada que sea contrario a su ánimo antojadizo o imperialista. ${ }^{98}$
\end{abstract}

Mientras Batlle Berres, y otros políticos uruguayos, intervenían activamente en la política argentina, en el mundo diplomático se estaban negociando otros procesos. Los norteamericanos hacían saber al canciller uruguayo que no sería conveniente incluir su iniciativa en el temario de la Conferencia de Río. ${ }^{99}$ El fracaso de la Doctrina Larreta — que quedó en el olvido en poco tiempo, salvo para los historiadores - se debía a razones tácticas. Por un lado tenía imprecisiones y vacíos, además de ser una generalización. Estados Unidos, diplomáticamente, comunicó que «una propuesta de una importancia tan fundamental requiere tiempo para cuajar», ${ }^{100} \mathrm{y}$ entre los que la rechazaban y aquellos países que pusieron reparos había una amplia mayoría. La adhesión categórica solo la habían expresado Costa Rica, Guatemala, Panamá, Venezuela y, obviamente, sus autores, Estados Unidos y Uruguay, seis de veintiún países no era mucho. ${ }^{101}$ Por otra parte, el Departamento de Estado, en concreto Spruille Braden, secretario de Asuntos Latinoamericanos, venía preparando una nueva injerencia que, esperaban, determinaría las elecciones de febrero a favor de los demócratas, el Libro Azul.

En consideración a la alianza tan especial que Uruguay tenía con Estados Unidos, el embajador uruguayo fue citado a una reunión reservada y «muy importante» en Blair House. A llegar fue recibido por Dean Acheson, secretario auxiliar de Estado y por Braden que «me expresaron en forma inequívoca su confianza en la identidad de opiniones y sentimientos de nuestros dos países respecto al asunto en deliberación» o sea, Argentina y

98 «A tres días de las elecciones en la Argentina», 21 de febrero de 1946, p. 2, AGNU, Fondo LBB, caja 21.

99 Muy reservado, Montevideo, 8 de enero de 1946, AHDMREU, Fondo MRE, serie Argentina, caja 3. La conferencia interamericana de Río, proyectada para el 20 de octubre de 1945, había sido suspendida a dos semanas de su reunión a pedido de los Estados Unidos, ya que no podían negociar un tratado de asistencia militar con un régimen como el argentino. Finalmente, la conferencia se reunió en 1947. Rapoport y Spiguel, 2009, 144. Cisneros y Escudé, 1993.

100 Idem.

101 Muy reservado, Montevideo, 21 de enero de 1946, AHDMREU, Fondo MRE, serie Argentina, caja 3 . 
el Libro Azul. La estima hacia el Uruguay no solo era una formalidad diplomática, ahora era cada vez más necesaria. Acheson reveló:

que el objeto de la reunión era dar cuenta de que el Departamento de Estado había remitido a las cancillerías [...] un memorándum sobre la Situación Argentina, que fue confeccionado durante muchos días y noches de incesante trabajo por el señor Braden con el auxilio de un importante personal y mediante el estudio de la voluminosa documentación recogida durante varios años [...] y enriquecida después de la victoria con gran cantidad de piezas encontradas en Alemania. ${ }^{102}$

Braden y Acheson fueron enfáticos y claros, Estados Unidos «no puede acordar confianza ni poner su fe en cualquier gobierno argentino que surja de entre los hombres que han figurado comprometidos en actividades nazi-fascistas en la Argentina desde el 7 de diciembre de 1941 y que por lo tanto [...] no podrán firmar con aquel un pacto eventual de asistencia mutua entre las naciones del hemisferio». ${ }^{103}$ Para el armado del TIAR debía haber gobiernos afines filosófica y doctrinariamente, dóciles, podría decirse. Así, el Departamento de Estado ayudaba a sus amigos en Argentina a ganar las elecciones, pero el efecto sería exactamente el contrario, le regaló al peronismo un arma que supo usar con maestría; que se tradujo en una consigna que recorrió el país: Braden o Perón.

Los sectores antiperonistas del Uruguay, o sea la mayoría del espectro político, apoyaron la publicación del Libro Azul. Tal vez Luis Batlle sea quien mejor resumió las razones de este apoyo, dedicándole varios programas al documento que sentenciaba la muerte de Perón. ${ }^{104}$ Defendió su necesidad y legitimidad antes del veredicto de las urnas, ya que era una nueva demostración del colaboracionismo norteamericano a favor de la democracia y la libertad. ${ }^{105}$

El 24 de febrero de 1946, Perón ganó las elecciones, limpias e incuestionables, y conmovió a la región. Era cierto, entonces, el apoyo popular que ahora se revelaba indiscutible. Los peligros podrían llegar a ser peores

102 Embajada del Uruguay, secreto, Washington, 12 de febrero de 1946, AHDMREU, Fondo MRE, serie Uruguay, caja 22.

103 Idem. La reunión en el marco de Blair House debió haber sido imponente para el embajador uruguayo, allí estaban Acheson — que en unos años sería secretario de Estado- Braden, el embajador Dawson y «no menos de veinte funcionarios del Departamento de Estado».

104 «Legítima influencia del Libro Azul en las próximas elecciones argentinas», 16 de febrero de 1946, p. 9, AGNU, Fondo LBB, caja 21. Sobre el impacto del Libro Azul en el escenario regional: Zanatta, 2013, 14-21.

105 «Repercusión del Libro Azul de Estados Unidos, referente a la Argentina en la prensa americana», 14 de febrero de 1946, p. 8, AGNU, Fondo LBB, caja 21. La legitimidad también se asociaba a que no podía aceptarse el silencio y continuar con el peligro peronista. 
teniendo en cuenta los temores sobre el expansionismo argentino. Para muchos era hora de reconsiderar la Doctrina Larreta. Quizá la respuesta argentina fue comenzar a bloquear al Uruguay, tanto en el turismo, complicando el flujo de turistas a sus playas, como limitando el comercio entre ambos países, especialmente el de trigo. La prensa norteamericana lanzó una campaña señalando que Perón quería derrocar al gobierno uruguayo con el objeto de poner en la presidencia a Luis Alberto de Herrera. ${ }^{106}$ Pronto, además, estallarían una serie de incidentes diplomáticos. En mayo de 1946, el embajador argentino en Uruguay, Gregorio Martínez, llamó «pelele» a Rodríguez Larreta en una fiesta en la legación de Bolivia, acusándolo de ser «un instrumento de Estados Unidos que se encargó de apuñalar a la Argentina por la espalda». ${ }^{107} \mathrm{Si}$ bien todo fue desmentido estaba en el aire la posibilidad de la presión que le iba a tocar vivir al Uruguay con un vecino al que se había enfrentado, al que había intentado derrotar y que finalmente había salido victorioso.

\section{Argentina y Uruguay: antecedentes y perspectivas a raíz de la emergencia del peronismo}

Cuando se produjo el golpe de Estado argentino en medio de la Segunda Guerra Mundial, el ascenso de los militares nacionalistas, vistos como pro-Eje, espantó a su pequeño vecino. El Uruguay estaba alineado con la causa aliada y tener en la casa de al lado al «enemigo» atizó los sentimientos nacionalistas y anti argentinos. El proceso político argentino de 1943 a 1946 generó todas las prevenciones posibles entre los sectores liberales y de izquierda del país, y estas se despertaron aun más con la aparición de la figura carismática de Perón, confirmación de la faz demagógica del fascismo. Uruguay echó mano a los recursos internacionales que tenía y que tan buenos resultados le habían dado, encontrar un aliado poderoso en quien respaldarse. Su «alianza histórica» había sido con el imperio británico. El batllismo, con su moderado pero firme nacionalismo, ya hacia 1940

106 Recortes de prensa de Santiago de Chile, 24 de abril de 1946, AHDMREU, Fondo MRE, serie Argentina, caja 5. Sobre la campaña electoral uruguaya del segundo semestre de 1946 y la intervención peronista, veáse Oddone, 2003, 41-45.

107 Nota MREU, Montevideo, 24 de mayo de 1946, AHDMREU, Fondo MRE, serie Argentina, caja 5. El embajador argentino fue aun más lejos, sostuvo que la independencia uruguaya había sido un error y que de haberse mantenido en la unión argentina hubiera sido el principal puerto del Río de la Plata. Ver también, en la misma ubicación, carta de Marques Castro a Rodríguez Larreta, México, 4 de junio de 1946. 
había comenzado la transición de hegemonías, del dominio británico a la alianza con los Estados Unidos.

Asimismo Uruguay tiene una singular «escuela o estilo diplomático». La reserva, la discreción, la prudencia y la apertura a todos es una de las características, la otra es la búsqueda de equilibrios que permitan sobrepasar dificultades. La «revolución de junio de 1943» rompió los equilibrios regionales y distorsionó las políticas hemisféricas, y la república oriental optó en principio por la prudente política de Serrato. Hemos visto los trabajos y las dificultades que tuvo este ex presidente, un viejo batllista, para no tensar la relación con Argentina. Su estrategia fue relativamente exitosa, inclusive hasta hábil. El episodio del retiro de embajadores, donde Uruguay se mantuvo hasta el final, da cuenta de un estilo que, quizá, debió haberse mantenido.

Sin embargo, el triunfo aliado trastocó todo el mapa geoestratégico del mundo y de la región. La aparición de los Estados Unidos como un imperio victorioso transformó definitivamente el relacionamiento hemisférico latinoamericano. Washington no aceptaría disidencias. Su impericia diplomática fue promisoria; los manejos de la crisis argentina muestran no solo la prepotencia del «nuevo rico» sino también la incomprensión sobre Latinoamérica y los latinoamericanos. En ese contexto Uruguay apostó al alineamiento total y con un estilo similar al de su aliado del norte. La Doctrina del ministro Larreta nació a imagen y semejanza de documentos del Departamento de Estado que la cancillería uruguaya manejaba y conocía. Si bien su propuesta fue un fracaso - tanto en lo político como en lo ideológico- alineó inevitablemente al Uruguay con los Estados Unidos y esta situación perduró en el tiempo.

Peter Waldmann sostiene que el peronismo fue una de las fases de la construcción de la nación argentina, que consistió en integrar a los excluidos, a los sectores populares. ${ }^{108}$ A su vez esa construcción nacional, por su estilo y sus formas, y por el tamaño del país así como por el proyecto político expansivo que encarnaba, generó prevenciones y también diferenciaciones en sus vecinos. Aquel proceso que se abrió en 1943 y perduró hasta 1955 terminó de integrar a la nación hermana, afectó al Uruguay y a los uruguayos afirmando aun más su identidad liberal, democrática y laica.

Recibido el 8 de septiembre de 2015

Aceptado el 17 de diciembre de 2015

108 Waldmann, 1986. 


\section{Referencias bibliográficas}

Buchrucker, Cristián, Nacionalismo y peronismo. La Argentina en la crisis ideológica mundial (1927-1955), Buenos Aires, Sudamericana, 1987.

Casal, Álvaro, La doctrina Larreta, Montevideo, Ediciones de la Plaza, 1997.

Cerrano, Carolina y López D’Alesandro, «Uruguay, Estados Unidos y el ascenso del peronismo», Semanario Brecha, Montevideo, 12 de septiembre de 2014, 12-14.

Cisneros, Andrés y Escudé, Carlos (eds.), Historia general de las relaciones exteriores de la República Argentina, Buenos Aires, Grupo Editor Latinoamericano, 1993, http://www.ucema.edu.ar/ceieg/arg-rree/historia (Consulta: 12/07/2008).

Figallo, Beatriz, El protocolo Perón-Franco. Relaciones hispano-argentinas: $1942-$ 1952, Buenos Aires, Corregidor, 1992.

Frega, Ana; Maronna, Mónica y Trochón, Yvette, Baldomir y la restauración democrática (1938-1946), Montevideo, EBO, 1987.

García Sebastiani, Marcela, Los antiperonistas en la Argentina peronista. Radicales y socialistas en la política argentina entre 1943-1955, Buenos Aires, Prometeo, 2005.

González de Oleaga, Marisa, El doble juego de la hispanidad. España y la Argentina durante la Segunda Guerra Mundial, Madrid, Ediciones UNED, 2002.

Halperín Donghi, Tulio, La Argentina y la tormenta del mundo. Ideas e ideologías entre 1930 y 1945, Buenos Aires, Siglo XXI, 2003.

Halperín Donghi, Tulio, La República imposible (1930-1945), Buenos Aires, Ariel, 2004.

James, Daniel, Resistencia e Integración. El peronismo y la clase trabajadora argentina 1946-1976, Buenos Aires, Sudamericana, 1990.

Luna, Félix, El 45, Buenos Aires, Hyspamérica, 1984.

Mercader, Antonio, El año del León. 1940: Herrera, las bases norteamericanas y el complot nazi, Montevideo, Aguilar, 1999.

Mercado, Silvia D., El relato peronista. Porque la única verdad no es la realidad, Buenos Aires, Planeta, 2015.

Oddone, Juan, El Uruguay entre la depresión y la guerra, Montevideo, Fundación de Cultura Universitaria, 1990.

Oddone, Juan, Vecinos en discordia. Argentina, Uruguay y la política hemisférica de los Estados Unidos. Selección de documentos. 1945-1955, Montevideo, Universidad de la República, Ediciones El Galeón, 2003.

Page, Joseph, Perón. Una biografía, Buenos Aires, Debolsillo, 2005 [1984].

Paradiso, José, Debates y trayectoria de la política exterior argentina, Buenos Aires, Grupo Editor Latinoamericano, 1993.

Piñeiro, Elena, La tradición nacionalista ante el peronismo. Itinerario de una esperanza a una desilusión, Buenos Aires, A-Z, 1997.

Potash, Robert, Perón y el GOU. Los documentos de una logia secreta, Buenos Aires, Sudamericana, 1982. 
Potash, Robert, El ejército y la política en la Argentina, 1928-1945. De Yrigoyen a Perón, Buenos Aires, Hyspamérica, 1985 [1969].

Rapoport, Mario, «Argentina y la Segunda Guerra Mundial: mitos y realidades», Estudios Interdisciplinarios de América Latina y el Caribe, 6-1, enero-junio 1995, http://eial.tau.ac.il/index.php/eial/article/view/1202/1230 (Consulta: 01/08/2006).

Rapoport, Mario y Spiguel, Claudio, Estados Unidos y el peronismo. La política norteamericana en la Argentina: 1949-1955, Buenos Aires, Grupo Editor Latinoamericano, 1994.

Rapoport, Mario y Spiguel, Claudio, Relaciones tumultuosas. Estados Unidos y el primer peronismo, Buenos Aires, Emecé, 2009.

Rein, Raanan, La salvación de una dictadura. La alianza Franco-Perón 19461955, Madrid, CSIC, 1995.

Rein, Raanan y Panella, Claudio (comps.), Peronismo y prensa escrita. Abordajes, miradas e interpretaciones nacionales y extranjeras, La Plata, Universidad Nacional de La Plata, 2008.

Rilla, José; Brando, Óscar y Quirici, Gabriel, Nosotros que nos queremos tanto. Uruguayos y argentinos, voces de una hermandad accidentada, Montevideo, Debate, 2013.

Rodríguez Ayçaguer, Ana María, «Entre la hermandad y el panamericanismo. El gobierno de Amézaga y las relaciones con Argentina. 1943», (Papeles de trabajo), Montevideo, Universidad de la República, Facultad de Humanidades y Ciencias de la Educación, 2004.

Rouquie, Alain, Poder militar y sociedad política en la Argentina 1943-1973, Buenos Aires, Emecé, 1994.

Ruiz Jiménez, Laura, La Argentina con porvenir. Los debates sobre la democracia y el modelo de desarrollo en los partidos y en la prensa (1926-1946), Madrid, Biblioteca Nueva, Fundación Ortega y Gasset, 2006.

Spinelli, María Estela, Los vencedores vencidos. El antiperonismo y la «revolución libertadora», Buenos Aires, Biblos, 2005.

Torre, Juan Carlos (dir.), Los años peronistas (1943-1955), VII Nueva Historia Argentina, Buenos Aires, Sudamericana, 2002.

Torre, Juan Carlos, La vieja guardia sindical y Perón. Sobre los orígenes del peronismo, Buenos Aires, Universidad Nacional de Tres de Febrero, 2006 [1990].

Tulchin, Joseph, La Argentina y los Estados Unidos. Historia de una desconfianza, Buenos Aires, Planeta, 1990.

Waldmann, Peter, El peronismo. 1943-1955, Buenos Aires, Hyspamérica, 1986.

Zanatta, Loris, Perón y el mito de la nación católica. Iglesia y Ejército en los orígenes del peronismo. 1943-1946, Buenos Aires, Sudamericana, 1999.

Zanatta, Loris, La Internacional Justicialista. Auge y ocaso de los sueños imperiales de Perón, Buenos Aires, Sudamericana, 2013.

Zubillaga, Carlos, Herrera. La encrucijada nacionalista, Montevideo, Arca, 1976. 